\title{
De Ceilán a Constantinopla: el Advertimiento de Andrés de Noronha, el Memorial de Felipe Botello y la correspondencia apócrifa entre los judíos de España y los de Constantinopla
}

Fernando Bravo López*

Universidad Autónoma de Madrid

En el presente artículo se arroja nueva luz sobre el Advertimiento que el obispo Andrés de Noronha envió a Mateo Vázquez, secretario de Felipe II, en 1584, texto que ha sido presentado por algún historiador como una evidencia muy temprana de la circulación de la famosa correspondencia apócrifa entre los judíos de España y los de Constantinopla. Examinamos el Advertimiento situándolo en su contexto gracias al estudio de la correspondencia que Noronha mantuvo Vázquez. Y, finalmente, analizamos el documento a partir de su comparación con el memorial -hasta hoy inédito- que el clérigo Felipe Botello entregó al inquisidor Martín de Salvatierra en 1569. Mediante este análisis demostraremos que prácticamente todo lo que Noronha decía en su documento es falso, producto de la tergiversación del memorial de Botello.

Palabras clave: Conversos; limpieza de sangre; conspiración judía; Inquisición; antijudaísmo.

From Ceylon to Constantinople: Andrés de Noronha's Advertimiento, Felipe Botello's Memorandum, and the Apocryphal Correspondence between the Jews of Spain AND those of Constantinople.- In this article we throw new light on the Advertimiento that bishop Andrés de Noronha sent to Phillip II's secretary, Mateo Vázquez, in 1584. This document has been presented by some historians as a very early evidence of the circulation of the famous apocryphal correspondence between the Jews of Spain and those of Constantinople. We analyse the Advertimiento by situating it in its context, thanks to the study of the correspondence that Noronha maintained with Vázquez. And finally, we analyse the document by comparing its content with that of the memorandum - unpublished until now - that the clergyman Felipe Botello handed to the inquisitor Martín de Salvatierra in 1569. Through that analysis we will demonstrate that almost all what Noronha said in his document was a forgery, a product of the misrepresentation of Botello's memorandum.

KEYwords: Conversos; Purity of blood; Jewish conspiracy; Inquisition; Anti-Judaism.

\footnotetext{
"fernandobravolopez@yahoo.es
}

Copyright: (C) 2016 CSIC. Este es un artículo de acceso abierto distribuido bajo los términos de una licencia de uso y distribución Creative Commons Attribution (CC-by) España 3.0. 


\section{Introducción: El Advertimiento de Andrés de Noronha}

En 1967 Francisco Cantera Burgos publicó un pequeño estudio en el que daba a conocer dos textos de carácter anticonverso escritos a finales del siglo XVI ${ }^{1}$. El primero de ellos era una especie de memorial conservado en el archivo del Instituto Valencia de Don Juan que llevaba por título Advertimiento de çierto negoçio sabido por orden de la Inquisiçión de Llerena. Según Cantera Burgos, el texto -que aparecía firmado con un escueto «D. A. obispo de Plasenzia»- era obra de Pedro González de Azevedo, quien lo habría escrito entre 1583 y 1591 y lo habría remitido a «un personaje influyente de la corte» de Felipe II.

En su Advertimiento, el obispo relataba cierto episodio ocurrido en un momento indeterminado del pasado. Según él, mientras estaba en «Portugal», tuvo una reunión con Martín de Salvatierra, obispo de Segorbe, quien en aquel entonces era inquisidor en Llerena. Durante esa reunión, el inquisidor le informó de que dos cristianos que habían estado cautivos en Constantinopla habían hecho declaración de que uno de ellos, que había sido esclavo de un judío, se enteró por medio de la hija de éste, la cual se había enamorado de él, de que los judíos de Portugal habían escrito a su padre pidiéndole consejo, y diciéndole que, debido a los sufrimientos que padecían, no habían encontrado mejor forma de actuar que hacer a sus hijos médicos y boticarios para, sirviéndose de sus conocimientos, matar a los cristianos y vengarse así de ellos. La chica enseñó la carta al cautivo, y también la respuesta que su padre había mandado a los judíos de Portugal. En ella les decía:

Que se consolassen y que perseverassen en aquel ardid de enseñar a sus hijos las sçiençias que deçían, y que, demás desso, procurassen hazerlos saçerdotes, para que, celebrando missa, hiziessen ydolotrar a los christianos; y también letrados para que, siendo juezes, quitassen las haziendas a los que no fuessen de su casta.

Ambas cartas fueron entregadas por la hija del judío al cautivo, y éste las entregó al inquisidor, quien, a su vez, las dio al obispo de Plasencia

${ }^{1}$ F. CANTERA Burgos, «El problema de los criptojudíos al escalar el trono Felipe III», en Homenaje al Excmo. Sr. Dr. Don Emilio Alarcos García (2 vols., Valladolid 1967) vol. 2, págs. 633-642. 
durante la reunión. El obispo, por su parte, decía haberlas mandado al rey Sebastián I de Portugal para su conocimiento. Éste, ante el descubrimiento de tamaña conspiración, lo único que hizo fue disponer que en la universidad de Coimbra se creasen veinte becas en medicina para «christianos viejos», y otras quince para farmacia.

El obispo también afirmaba que, con respecto a los jueces, en Portugal había costumbre de que fueran cristianos viejos, y que el Concilio había dispuesto lo mismo para la ordenación de clérigos. Como conclusión de todo lo dicho, sugería que se privara a los «christianos nuevos» «de toda honra y preeminencia», dado el peligro que suponían para el reino, y pedía que todo ello se pusiera en conocimiento del rey en cuanto hubiera ocasión. Además, señalaba que él siempre había tenido problemas con los conversos y que últimamente, en Plasencia, se había montado una «grande revolución» entre ellos porque no quería ordenar a clérigos que tuvieran «esta nota» ${ }^{2}$.

Tras la exposición del contenido del documento, Cantera Burgos no se extendía más allá en el asunto. No se preguntaba por la verosimilitud del relato del obispo, ni sobre sus fuentes, ni tampoco por la identidad de su destinatario -al que el autor del documento siempre se refiere con un «v.m.»-. De hecho, en su interpretación era evidente que cometía un error al atribuirlo a Pedro González de Azevedo, ya que éste fue obispo de Plasencia entre 1594 y 1609, por lo que no pudo coincidir con el obispado de Martín de Salvatierra en Segorbe (1583-1591).

Fue David Goodman quien en 1988 detectó ese error de Cantera Burgos -aunque sin citarlo, todo sea dicho-, y fue él quien atribuyó correctamente el Advertimiento a Andrés de Noronha, quien, efectivamente, fue obispo de Plasencia entre 1581 y $1586^{3}$. El texto, por tanto, databa de los años 80. Gracias a esa correcta identificación, y a una mejor lectura del documento, Goodman pudo determinar que la reunión entre Noronha y Salvatierra que se menciona en él no tuvo lugar en Portugal por casuali-

${ }^{2}$ Instituto Valencia de Don Juan (en adelante IVDJ), envío 91, caja 131, doc. 473. El texto ha sido transcrito en F. SOYER, «The Anti-Semitic Conspiracy Theory in SixteenthCentury Spain and Portugal and the Origins of the Carta de los judios de Constantinopla: New Evidence», Sefarad 74:2 (2014) págs. 369-388.

${ }^{3}$ D. Goodman, Poder y penuria: gobierno, tecnología y sociedad en la España de Felipe II (Madrid 1990) págs. 247-248. 
dad, sino porque el primero era obispo de Portalegre cuando el segundo era inquisidor en Llerena. De hecho, era «Portalegre» y no «Portugal» -como erróneamente había leído Cantera Burgos- lo que decía el documento.

Goodman, sin embargo, no aclaraba quién era el destinatario del Advertimiento, pero sí recordaba al lector que la conspiración judía descrita en él recordaba sobremanera a la que se reflejaba en la famosa correspondencia apócrifa entre los judíos de España y los de Constantinopla ${ }^{4}$. Efectivamente, en la respuesta de los judíos de Constantinopla a la petición de consejo que supuestamente les realizaron los judíos de España podía leerse:

A lo que dezís qu'el Rey d'Espanna os haze voluer Christianos, que lo hagáis pues no podéis hazer otro. A lo que dezís que os mandan quitar vuestras haziendas, hazed vuestros hijos mercaderes, para que poco a poco les quiten las suyas. A lo que dezís que os quitan las vidas, hazed vuestros hijos médicos y apotecarios, para que les quiten las suyas. A lo que dezís que os destruyen vuestras Sinagogas, hazed vuestros hijos clérigos y theólogos, para que les destruyan sus templos. I a lo que dezís que os hazen otras vexationes, procurad que vuestros hijos sean abogados, procuradores, notarios, y consejeros, y que siempre entiendan en negotios de Repúblicas, para que sujetándolos ganéis tierra, y os podáis vengar d'ellos, y no salgáis d'esta orden que os damos, porque por experientia veréis que de abatidos, vernéis a ser tenidos en algo ${ }^{5}$.

Ante esa semejanza, cabía preguntarse: ¿existía quizás alguna relación entre la correspondencia apócrifa y el Advertimiento de Noronha? ¿Eran las cartas que tan famosas llegarían a hacerse las mismas que los cautivos entregaron a Salvatierra? ¿Eran, por tanto, reales las cartas? ¿Las habían obtenido los cautivos de manos de la hija del propio destinatario de la

\footnotetext{
${ }^{4}$ D. Goodman, Poder y penuria, pág. 247, nt. 240.

${ }^{5}$ De la correspondencia apócrifa entre los judíos de España y los de Constantinopla existen varias versiones. Cito aquí siguiendo la primera versión impresa: J. DE MEdRano, La silva curiosa (París 1583) págs. 244-245. Existe otra edición de la obra de Medrano fechada en Zaragoza en 1580, pero, como ha demostrado Alcalá Galán, se trata de la misma edición de París, solo que se puso a la venta con datos falsos de edición; véase J. DE Medrano, La silva curiosa de Julián de Medrano, estudio y edición crítica de Mercedes Alcalá Galán (New York 1998) pág. 4. Sobre la historia de esta correspondencia y su tratamiento por la historiografía véase F. BRAVo LóPEz, «La historiografía ante la correspondencia apócrifa entre los judíos de España y los de Constantinopla: una revisión crítica», Studia Historica. Historia Moderna 38:2 (2016 [en prensa]).
} 
pregunta y autor de la respuesta? ¿O se habrían inventado toda la historia? ¿Habrían sido los cautivos los autores de esa famosa falsificación y los responsables de haberla puesto en circulación?

Por de pronto, era evidente que existía una diferencia principal entre ambos textos: el de Noronha se refería a los judíos de Portugal, y, en cambio, las cartas se referían -al menos en su versión más antigua ${ }^{6}$ - a los judíos de España. ¿Quizás el obispo de Plasencia se había permitido alterar el contenido de las cartas para ajustarlo a sus intereses en pos de que el rey de Portugal estableciera una política de limpieza de sangre en su país? También existía otra diferencia importante: en la historia de Noronha, el «ardid» de hacer a sus hijos médicos y boticarios había sido una iniciativa de los propios judíos de Portugal, mientras que en las cartas era uno de los consejos de los judíos de Constantinopla. Además, en éstas la relación de oficios era más rica: incluía mercaderes, procuradores, notarios, consejeros y otros oficios que les permitieran entender en «negotios de Repúblicas». Así que el contenido no era totalmente idéntico. A pesar de ello, era evidente que alguna relación tenía que existir entre ambos textos, ¿pero cuál era?

En 2014 François Soyer trató de responder a todas esas cuestiones. Lo hizo en un artículo en el que presentaba el Advertimiento de Noronha como una «nueva evidencia» a tener en cuenta a la hora de dilucidar cuál fue la historia de la correspondencia apócrifa entre los judíos de España y los de Constantinopla ${ }^{7}$. En su trabajo, tras hacer un resumen de la historia de las famosas cartas, exponer su importancia en la tradición antijudía europea, y detenerse en repasar lo que se sabía acerca de su origen, pasaba a analizar el memorial del obispo de Plasencia.

\footnotetext{
${ }^{6}$ En 1641 el abate Bouis publicó una versión de las cartas en la que los judíos que preguntaban eran de la ciudad francesa de Arlés, y lo hacían en provenzal; véase J. BouIs, La royalle couronne des roys d'Arles (Avignon 1641) págs. 475-477. La carta de los judíos de Arlés fue luego la que más popularidad adquirió entre los antisemitas de finales del XIX y principios del XX. Existen otras versiones que no tuvieron trascendencia alguna, pero que sitúan a los destinatarios de la pregunta en Babilonia (caso del manuscrito del siglo XVII Espagnol 354, de la Biblioteca Nacional de Francia) o en Ámsterdam (en B. R. Noydens, Visita general y espiritual colirio de los Iudios; y promptuario católico de los más principales fundamentos de la fe y religion christiana [Madrid 1662] pág. 8).

${ }^{7}$ F. SOYER, «The Anti-Semitic Conspiracy Theory».
} 
En su análisis, aunque mencionaba el trabajo previo de Cantera Burgos y su error de atribución, no decía nada de la aportación de David Goodman y presentaba la atribución del texto a Noronha como si de una novedad se tratase. Pero, si bien la autoría ya era conocida, seguía sin serlo el destinatario. Con respecto a esto, Soyer señalaba que, puesto que el Instituto Valencia de Don Juan conservaba documentación de los secretarios reales Mateo Vázquez y Antonio Pérez, era posible que el documento estuviera destinado a alguno de ellos. Soyer también aportaba una datación más precisa: el documento tenía que ser de entre 1583 y 1586, años en los que coincidieron Noronha y Salvatierra en sus respectivos obispados de Plasencia y Segorbe.

En cualquier caso, aparte de concretar más el marco cronológico en el que el documento fue redactado y apuntar esa hipótesis acerca de la identidad del destinatario, lo novedoso del artículo de Soyer era la forma en que trataba el testimonio del obispo como una «referencia muy temprana» de la existencia y circulación de la correspondencia apócrifa entre los judíos de España y los de Constantinopla. Efectivamente, a pesar de que en el documento se daba cuenta de un encuentro sucedido unos veinte años antes, Soyer parecía aceptar que la historia resultaba verídica: que el encuentro con Salvatierra se produjo tal y como Noronha relataba, que el inquisidor efectivamente le entregó las cartas, que aquél las envió al rey de Portugal y que influyeron en él hasta el punto de que le movieron a crear esas becas para «cristianos viejos» en la Universidad de Coimbra. Soyer incluso parecía dar crédito a la historia acerca de los cautivos que estuvieron en Constantinopla y obtuvieron las cartas.

Según este autor, la reunión entre Salvatierra y Noronha pudo haberse producido entre los años 1566 -año en el que el primero fue nombrado inquisidor en Llerena ${ }^{8}$-, y 1567 , antes necesariamente de que se crearan las mencionadas becas en la Universidad de Coimbra, algo que tuvo lugar efectivamente en $1568^{\circ}$. Si es así, la declaración de los cautivos -si la

${ }^{8}$ Soyer no menciona de qué fuente obtiene esta fecha para el nombramiento de Salvatierra como inquisidor en Llerena, pero es probable que la haya obtenido de E. DE GARIBAY, Memorias de Garibay / Memorial histórico español: colección de documentos, opúsculos y antigüedades que publica la Real Academia de la Historia. Vol. VII (Madrid 1834) págs. 229-230.

${ }^{9}$ Sobre esto véase T. Braga, Historia da Universidade de Coimbra. 2 vols. (Lisboa 1892-1895) vol. 1, pág. 779. 
realizaron ante el mismo Salvatierra- tuvo que haber tenido lugar en un momento indeterminado entre 1566 y la fecha de la reunión. Era esa datación la que permitía asegurar, según Soyer, que el Advertimiento probaba que la correspondencia entre los judíos de España y los de Constantinopla circulaba ya antes de 1566. Al menos, eso parecía, si lo que Noronha contaba era cierto.

Pudiera parecer que es éste un tema menor sobre un documento casi anecdótico dentro una historia, la de la ideología antijudía, plagada de ese tipo de acusaciones. Pero hay que recordar que la famosa correspondencia a la que nos estamos refiriendo es, como el propio Soyer ha mostrado, uno de los textos antijudíos más importantes de la historia europea. Sin duda, ha sido uno de los que más trascendencia posterior ha tenido. Impresas por primera vez en La silva curiosa de Julián de Medrano (París, 1583), la correspondencia ha sido transmitida hasta nuestros días por gran cantidad de autores que la han considerado verídica; desde España a Francia, Portugal, Alemania, Italia, y hasta el mundo de Internet de nuestros días ${ }^{10}$. Fue especialmente entre finales del siglo XIX y la primera mitad del XX cuando la correspondencia fue más profusamente utilizada por la propaganda antisemita europea, mostrada como antecedente claro de Los protocolos de los sabios de Sión y como prueba de su veracidad ${ }^{11}$.

${ }^{10}$ Una búsqueda en Google de expresiones contenidas en la correspondencia como «príncipe de los judíos de Constantinopla» ofrece gran cantidad de ejemplos de páginas web que utilizan esos textos como prueba de la existencia de un complot judío internacional desde hace siglos. Lo mismo cabe decir si realizamos la búsqueda en cualquier otro idioma europeo.

${ }^{11}$ La encontramos en obras tan importantes del antisemitismo europeo como E.A. Chabauty, Les Juifs, nos maîtres! Documents et développements nouveaux sur la question juive (Paris 1882) págs. 4-19; É. DRUMONT, La France Juive: essai d'histoire contemporaine. 2 vols. (Paris 1886) vol. 1, págs. 216-217; H. DESPORTES, Le mystère du sang chez les juifs de tous les temps (Paris 1890) págs. 336-337; L. Meurin, La francmaçonnerie, synagogue de Satan (Paris 1893) págs. 207-209; TANYeman, La Europa judía: brevenoticia del origen de esta raza, de su conductay de sus actuales aspiraciones (Barcelona 1896) págs. 40-41. Y también en varias ediciones de Los protocolos: U. Gohier (ed.), Protocoles des sages d'Israël (Paris 1925) págs. 134-135; The Protocols of the Meetings of the Learned Elders of Zion. With a Preface and Explanatory Notes, Translated from the Russian Text by Victor E. Marsden, formerly Russian Correspondent of "The Morning Post" (s.l. 1934) págs. 98-99; G. zUR BeEk (ed.), Die Geheimnisse der Weisen von Zion (4ª ed. Berlin 1920) págs. 4-5; Protocolos de las reuniones de los sabios de Sión. Traducción de la obra en ruso de 
Sin embargo, a pesar de su importancia histórica, se sabe aún muy poco acerca de su origen. Se ha señalado repetidamente que el primero que hizo uso de ella fue el arzobispo de Toledo Juan Martínez Silíceo, que supuestamente la habría utilizado para dar fuerza a su postura en favor de la introducción del estatuto de limpieza de sangre de la catedral de Toledo. Esta idea ha sido defendida por autores como Adolfo de Castro, Albert Sicroff, Julio Caro Baroja o Benzion Netanyahu ${ }^{12}$; pero, en realidad, no hay ninguna prueba de ello. Castro señaló a Silíceo siguiendo lo que decía una de las copias del Libro verde de Aragón que incluía las cartas, pero fue más allá de lo que el propio texto decía -que sólo afirmaba que el arzobispo las había encontrado ${ }^{13}$ - para señalar al arzobispo como su autor. El resto de autores, aun cuando señalaban que no había pruebas de la autoría de Silíceo, siguieron manteniendo como veraz la afirmación del Libro verde.

Pero lo cierto es que en la documentación que se conserva del pleito que el arzobispo mantuvo con parte de su cabildo para la aprobación del estatuto no se encuentran las cartas, ni mención alguna a ellas, a pesar de lo aficionado que era el arzobispo a hacer uso de todas las leyendas antijudías que caían en su manos para dar fuerza a su argumento. Si el arzobispo no las mencionó, ni tampoco lo hicieron sus contradictores con

Nilus por Víctor E. Marsden ... Traducido del inglés al español por F.J.Y. (Bilbao 1932) págs. 25-28.

${ }^{12}$ A. De Castro, Historia de los judíos en España (Cádiz 1847) págs. 137-142; J. CARo Baroja, Los judios en la España moderna y contemporánea, I (4a ed. Tres Cantos 2000) págs. 423-424; A. A. Sicroff, Los estatutos de limpieza de sangre: controversias entre los siglos XV y XVII (Madrid 1985) págs. 148-149, esp. nt. 181; B. NetANYAHU, Los orígenes de la Inquisición en la España del siglo XV (Barcelona 1999) págs. 963-966. Otros muchos autores han defendido lo mismo; véase, por ejemplo, R. CARRASCO, «La nueva Jerusalén y la memoria judeoconversa (siglos XVI - XVII)», en La Inquisición y la sociedad Española, eds. R. CArrasco, R. García CÁrcel y J. Contreras (Valencia 1996) págs. 9-30: 26; G. Álvarez Chillida, El antisemitismo en España: la imagen del judío, 1812-2002 (Madrid 2002) págs. 45-46; R. AmRan, «Calumnias y falsificación histórica: dos casos de correspondencia apócrifa relacionadas con judíos hispanos durante el medioevo», Cahiers de Linguistique Hispanique Médiévale 29 (2006) págs. 317-326; F. Quero, Juan Martínez Silíceo (1486?-1557) et la spiritualité de l'Espagne pré-tridentine (Paris 2014) pág. 230.

${ }^{13}$ «Un día, reuoluiendo unas antiquíssimas scripturas en el archiuo de Toledo, halló una copia y traslado de una carta original, la qual imbiaron los judíos de Espan[n]a a los judíos de Constantinopla»; El libro verde de Aragón, ed. M. Combescure (Zaragoza 2003) págs. 209-211. 
el objetivo de rebatirlas, ni tampoco se mencionan en la correspondencia que sobre el caso se conserva, lo más seguro es que ninguno de los protagonistas de ese conflicto las conociera ${ }^{14}$.

Las cartas de los judíos no se utilizaron, por tanto, durante el proceso de aprobación y confirmación del estatuto de limpieza en la catedral de Toledo -es decir, entre 1547 y 1556-. Y tampoco se ha encontrado ninguna referencia posterior a ellas hasta 1575 , cuando supuestamente el obispo Diego de Simancas incluyó una mención expresa en su Defensa del estatuto de Toledo; o así, al menos, lo han defendido algunos autores $^{15}$. Sin embargo, la verdad es que el famoso persecutor del arzobispo Carranza no mencionó la existencia de ninguna correspondencia, sino que se refirió a un rumor, una leyenda que corría por la época:

Muchos de los judíos quando fueron echados de España a otras partes, por no dejar tan buena y fértil tierra, rescivieron la fee Cathólica, pero fingidamente, como después paresçió por la obra. Porque aviéndoseles señalado término y tiempo para que se determinasen si querían ser christianos, y si no que saliesen d'España con la yra de Dios y nunca jamás volviesen a ella, fue fama que tubieron lugar de consultar las sinogas [sic] de otros reynos, de las quales les fue dado avisso que fingiesen que querían ser christianos para que por esta vía pudiesen haçer mayores daños a los christianos, diçiendo: "por esta vía procuraréis con vuestra theología contraminar [sic] su ley;

${ }^{14}$ Se conservan muchas copias del llamado Libro de causas que el arzobispo presentó ante el Consejo Real de Castilla en el verano de 1548 para defender la necesidad de la introducción del estatuto. Nosotros hemos podido localizar 28, conservadas en bibliotecas y archivos de España, Francia, México y Reino Unido. De esas copias sólo 3 contienen las cartas: British Library, Egerton ms. 415; Biblioteca Nacional de Francia, ms. Espagnol 354; y Real Academia de la Historia, ms. 9/1208. Sin embargo, los dos primeros son manuscritos misceláneos en donde las cartas no aparecen como parte del Libro de causas, sino en otro lugar. Sólo en el caso del 9/1208 las cartas aparecen inmediatamente después del Libro, pero se trata de una copia de principios del siglo XVII, de después, por tanto, de que las cartas hubieran aparecido impresas. Además, en el Archivo General de Simancas —Cámara de Castilla, leg. 291 - se conserva documentación relativa al pleito presentado ante el Consejo Real, en la cual tampoco hay mención alguna a las cartas. Y tampoco la hay en las copias que han sobrevivido del texto que presentaron los contradictores del estatuto; véase Archivo Histórico Nacional, Sección Nobleza (en adelante AHNOB), Frías, C. 115, D. 31; AHNOB, Osuna, C. 3103, D. 6; Biblioteca Nacional de España (en adelante BNE) ms. 9175, fols. 54r-59v; BNE ms. 732, fols. 138r-149r; BNE ms. 1703, fols. 1r-17v.

${ }^{15}$ Véase Sicroff, Los estatutos, pág. 198, y J. CARo Baroja, Los judíos en la España moderna y contemporánea. Vol II (4ª ed. Tres Cantos 2005) págs. 430-432. 
siendo letrados les podréis quitar sus bienes; siendo médicos les quitaréis las vidas sin que por ello os castiguen, y alcançando y consiguiendo de la manera que os fuere posible los veneficios eclesiásticos, usaréis mal de los sacramentos; si entráredes en religión, perturbaréis la paz y concordia; finalmente, deprenderéis todos los demás offiçios y artes y procuraréis los cargos públicos para que sin trabajo y dificultad podáis ser señores de sus bienes y aciendas". Y si por ventura esto no es ansí, sino que se les imputó falsamente, con todo el subcesso de las cosas declaro quán cercano está a la verdad, porque se a allado que muchos dellos se convirtieron falsa y fingidamente, y se están en su ceguera e ynfidelidad; otros an salido eresiarcas, algunos letrados y abogados an gastado y robado las aciendas de los litigantes, algunos médicos mataron muchos christianos, dándoles veneno en las purgas, y, en suma, ellos an puesto en execución todo aquello que la fama, o fábula, arriba dicha dibulgó de los judíos ${ }^{16}$.

Como se ve, Simancas no habla de que existieran unas cartas, ni manuscritas ni impresas, que se pudieran consultar para comprobar la veracidad del relato. Se refería claramente a un rumor que, además, no resultaba del todo creíble; si bien, a su juicio, describía bien cuál había sido el comportamiento real de los judíos en el momento de la expulsión. Pero, en cualquier caso, aunque Simancas se hubiera referido realmente a la existencia de la famosa correspondencia, el Advertimiento de Noronha aún contendría una referencia anterior en unos 8 o 9 años, lo que lo convertiría, de hecho, en el testimonio más antiguo de la existencia de las apócrifas cartas entre los judíos de España y Constantinopla. Pero, ¿es así?

\section{De Andrés de Noronha a Mateo VÁZquez}

El autor de nuestro Advertimiento nació en Vila Real hacia $1522^{17}$. Hijo ilegítimo de João de Noronha, gobernador de Ceuta, nieto de Fernando de Meneses, segundo marqués de Vila Real, y sobrino de Afonso de Noronha, virrey de la India portuguesa, era miembro de una de las familias más importantes de Portugal. Mientras su hermano Antão siguió la

${ }^{16}$ BNE ms. 2592, págs. 19-20; véase la versión original en latín: D. DE SimAnCAS, Defensio statuti toletani a sede apostolica saepe confirmati (Amberes 1575) págs. 18-19.

${ }^{17}$ En una carta sin fecha, pero probablemente de principios de 1582, Noronha afirma tener 60 años; véase IVDJ, envío 89, caja 126, doc. 592. 
carrera de las armas y llegó a ser, como su padre, gobernador de Ceuta, y, como su tío, virrey de la India portuguesa, él siguió la carrera eclesiástica. Estudió en la Facultad de Cánones de la Universidad de Coimbra, donde se graduó, y, tras ello, se ordenó sacerdote. Fue deán de la Capilla Real, inquisidor, presidente de la Mesa de Conciencia y, en 1560, fue nombrado obispo de la diócesis de Portalegre ${ }^{18}$.

Fue durante su estancia en Portalegre cuando sobrevino la crisis dinástica en Portugal, y fue entonces cuando Noronha mostró abiertamente su apoyo a Felipe II en contra de las aspiraciones de don Antonio de Portugal. José P. Pavía afirma que Noronha se unió al bando filipino siguiendo la postura adoptada por su primo Manuel de Meneses, quinto marqués de Vila Real. Por contra, Ana López-Salazar afirma que fue al revés: «a principios de septiembre de 1579, António Matos de Noronha entró en Portugal y comenzó inmediatamente su tarea de ganar adeptos. Antes de dirigirse a Lisboa, pasó por Portalegre a tratar con el obispo, D. André de Noronha, al que consideraba deudo y amigo y que, en su opinión, estaba decantado por el lado filipino.» Y, una vez ganado Andrés de Noronha para la causa filipina, fue él el que consiguió que se uniera a ella el marqués de Vila Real ${ }^{19}$.

Sea como fuere, lo cierto es que, durante la crisis sucesoria, Noronha ciertamente jugó un papel como informador y como intermediario entre la Corte de Felipe II y los nobles de la zona de Portalegre que querían someterse al rey. Así, por ejemplo, Noronha informó al rey de la fuerza que

${ }^{18}$ Todos los datos sobre su familia y vida provienen de G. GonZález DÁvILA, Teatro eclesiástico de las Iglesias metropolitanas y Catedrales de los Reynos de las dos Castillas. 4 vols. (Madrid 1645) vol. 2, pág. 506; A. C. DE SousA, Historia genealógica da Casa Real portuguesa. 13 vols. (Lisboa 1735-1748) vol. 5, págs. 249-250. Ambos autores aseguran que Noronha fue rector de la Universidad de Coimbra, cosa que no consta en el listado de rectores que ofrece la propia Universidad; véase http://www.uc.pt/sobrenos/historia/ reitores_xiii_xvi [fecha de consulta: 1 de julio de 2016].

${ }^{19}$ Véase J. P. Pavía, «Bishops and Politics: the Portuguese Episcopacy during the Dynastic Crisis of 1580», E-Journal of Portuguese History 4:2 (2006), https://www.brown. edu/Departments/Portuguese_Brazilian_Studies/ejph/html/issue8/html/jpaiva_main.html [fecha de consulta: 4 de julio de 2016], y A. I. LóPEZ-SALAZAR, Inquisición y política: el gobierno del Santo Oficio en el Portugal de los Austrias (1578-1653) (Lisboa 2011) pág. 45. Véase también, sobre la actitud de la Iglesia portuguesa ante la crisis dinástica, F. PALOMO, «Para el sosiego y quietud del reino: en torno a Felipe II y el poder eclesiástico en el Portugal de finales del siglo XVI», Hispania 64:1, núm. 216 (2004) págs. 63-93. 
el partido favorable a don Antonio tenía en Portalegre, de sus amenazas y sus maquinaciones -sobre lo que volveremos después-; informó también del discurso dado por don Antonio para animar a la defensa de Setúbal; y ejerció de intermediario entre la Corte y ciertos notables de la villa de Crato que deseaban mostrar su fidelidad a Felipe. De todo ello informó Noronha al rey a través de su correspondencia con el secretario Mateo Vázquez ${ }^{20}$.

Mateo Vázquez fue siempre el principal contacto de Noronha con la Corte de Felipe II. La correspondencia entre ambos existió, por lo que hemos podido constatar, desde, al menos, mediados de 1580. Sin embargo, es muy posible que tuvieran relación epistolar desde bastante antes, puesto que en julio de ese año el obispo ya agradecía a Vázquez que le hiciera todas las mercedes que le pedía -suponemos que en cartas anteriores- $-^{21}$, y ya para agosto había adquirido tal familiaridad con el secretario que incluso llegaba a considerarlo como si fuera su hermano ${ }^{22}$.

No sabemos cuándo empezaron su relación epistolar, pero lo que sí sabemos es que, al menos durante los siguientes cuatro años, Noronha y Vázquez mantendrían una correspondencia muy frecuente ${ }^{23}$. Tenemos también constancia de una carta escrita directamente a Felipe II $^{24}$, pero en general, el contacto de Noronha con el rey se realizó siempre a través de su secretario.

A través de él trasladaba sus inquietudes y sentimientos al rey, y le pedía los favores o mercedes que necesitaba. Así, por ejemplo, en julio de 1580, ante el descontento que había detectado en la población de Portalegre porque Felipe II no había confirmado aún los privilegios de la ciudad, Noronha pedía

${ }^{20}$ IVDJ, envío 5, tomo II, doc. 182; IVDJ, envío 5, tomo II, doc. 183; IVDJ, envío 5, tomo II, doc. 184; IVDJ, envío 5, tomo II, doc. 186.

${ }^{21}$ IVDJ, envío 5, tomo II, doc. 182.

22 "Que de vuestra merced a un hermano solo que tube no hago ninguna diferencia en el amor, verdad y deseo, y conforme a esto deseo me vuestra merced mande siempre servirle»; en IVDJ, envío 91, caja 130, doc. 119.

${ }^{23}$ Hemos encontrado un total de 15 cartas dirigidas por el obispo al secretario, pero, a tenor de lo que se puede colegir del contenido de las consultadas, tuvieron que existir muchas más que no hemos podido localizar o que no se han conservado. En algunos periodos la correspondencia es tan asidua como para incluir tres cartas en el mismo mes -caso de julio de 1580-.

${ }^{24}$ IVDJ, envío 91, caja 130, doc. 114. 
a Vázquez que suplicara al rey que realizara tal confirmación para calmar los ánimos. ${ }^{25}$. Incluso en un momento tan delicado como el del luto por la muerte de la infanta María, Noronha escribió al rey a través de Vázquez para dar su pésame $^{26}$. La relación con Vázquez parece que verdaderamente era de mucha cercanía, porque en junio de 1583 Noronha fue uno de los que recibió la genealogía que el secretario hizo componer, y que después envió a todos sus allegados, para demostrar su ascendencia ilustre y desmentir algunos rumores que habían corrido acerca de su origen poco «limpio».

Una de las principales inquietudes que el obispo trasladó al secretario fue la que le provocaba su relación con los «confessos». Ya desde los tiempos de la crisis sucesoria, Noronha identificaba al partido contrario a Felipe II como «confessos y criados de don Antonio», los cuales, a su parecer, «echan mano de quoalquiera cosa aparente para amutinar el pueblo» ${ }^{28}$. Y más tarde, cuando ya había sido tomada Lisboa, se congratulaba de que se hubiera acabado con «aquel imperio de don Antonio, tan violento, aprobado por mugeres, negociado por frailes y sustenido con dineros de confessos» ${ }^{29}$.

Según el obispo, los «confessos» de Portalegre apoyaban a don Antonio y, por esa misma razón, le odiaban, como principal representante, junto al conde Álvaro da Silva, de la causa filipina en la ciudad. El odio de los «confessos» llegaba hasta el punto de querer atentar contra su vida. Eso, al menos, es lo que le contó a Vázquez en octubre de 1580. Al parecer, un fraile partidario de don Antonio había ido a verle y le había contado que «los confessos y algunos escuderos» se dedicaban a propalar bulos acerca de que Felipe II estaba muerto, pero que se guardaba en secreto, y querían proclamar rey a don Antonio. Además, el fraile sabía con certeza que a Noronha le «deseaban mucho la muerte», por lo que le recomendaba que se guardase de tomar «cosa de botica ni que viniesse por mano de judío». El obispo, por su parte, transmitió al fraile entereza, desmintió la supues-

${ }^{25}$ IVDJ, envío 5, tomo II, doc. 182.

${ }^{26}$ IVDJ, envío 91, caja 130, doc. 115.

${ }^{27}$ IVDJ, envío 44, caja 57, doc. 19; véase también J. L. GonZalo SÁnchez-Molero, «Mateo Vázquez de Leca: un secretario entre libros. 2. La biblioteca (y 2)», Hispania Sacra 61, extra 2 (2014) págs. 279-321, esp. nt. 28.

${ }^{28}$ IVDJ, envío 5, tomo II, doc. 182.

${ }^{29}$ IVDJ, envío 5, tomo II, doc. 185. 
ta muerte del rey, y le aseguró que no huiría de la ciudad. Sin embargo, parece que el odio que le mostraba parte de la población de Portalegre había hecho mella en él, porque pidió encarecidamente al secretario que transmitiera al monarca su deseo de ser destinado a otra diócesis, pues no quería vivir «entre gente que me no quiere bien» ${ }^{30}$.

Un año después, el rey había hecho realidad sus deseos. Consiguió para él la diócesis de Plasencia, a donde el obispo se trasladó con gran alegría. Más alegría sintió por el recibimiento que la ciudad le ofreció: «me recibieron con el maior aplauso y contento de todos en general que jamás se vio ni hizo a ningún prelado», contaba a Vázquez a finales de abril de $1582^{31}$. En mayo de ese mismo año el obispo convocó un sínodo diocesano en donde se aprobaron las constituciones del obispado, algo que, según él, no habían conseguido los obispos anteriores desde hacía mucho tiempo. Todos los miembros del cabildo las aprobaron sin poner ningún pero, para gran alegría de Noronha ${ }^{32}$. Todo iba muy bien, al menos al principio.

Sin embargo, parece que la situación se torció poco tiempo después. A lo largo del año 1583 debieron de surgir algunos problemas, de los cuales nuestra única referencia es la mención que a ellos se hace en el Advertimiento. A pesar de que en las constituciones no se introducía ningún estatuto de limpieza de sangre ${ }^{33}$, parece que el obispo no deseaba ordenar a clérigos que pudieran ser identificados como descendientes de conversos. Esto había provocado una reacción hostil por parte del cabildo ${ }^{34}$.

${ }^{30}$ IVDJ, envío 5, tomo II, doc. 186.

${ }^{31}$ IVDJ, envío 89, caja 126, doc. 593.

${ }^{32}$ IVDJ, envío 89, caja 126, doc. 597.

${ }^{33}$ Noronha decía querer imprimir las constituciones de 1582 , pero hasta nosotros sólo han llegado las que se votaron en 1585, en las cuales sólo se exige limpieza de sangre a los niños del coro; véase Estatutos de la santa iglesia cathedral de Plasencia, fechos y confirmados por el ilustrísimo señor don Andrés de Noroña, obispo de Plasencia (Madrid 1704) fol. 17v. En cualquier caso, sería necesario revisar las Actas Capitulares para conocer en detalle el origen y desarrollo del conflicto que se menciona en el Advertimiento, algo que, por desgracia, no hemos podido hacer hasta ahora, debido a las obras de restauración del Archivo y de la Biblioteca de la catedral, que impiden el acceso a los fondos.

${ }^{34}$ Como hemos señalado más arriba, en el Advertimiento el obispo recordaba: «Y agora en Plasenzia, por averme con rigor con los que tienen esta nota para averse de ordenar de clérigos, que no los quiero admittir, ay tan grande revoluçión entre ellos como por otras mías tengo significado a vuestra merced». 
Pero la gota que colmó el vaso fue un suceso que se desató en Plasencia mientras el obispo se encontraba en Béjar, en febrero de 1584. Al parecer, el alcalde mayor de Plasencia había entrado a mano armada en el Palacio episcopal y había abierto la cárcel para sacar de ella a un preso. El concejo había puesto un juez para resolver el asunto, pero el alcalde, por su parte, había ido a la Corte para impedir las pesquisas y pedir perdón. Ante este episodio, Noronha pedía a Vázquez que no se impidiera la investigación, y señalaba que el alcalde «es muy moço y ninguna cosa limpio, según me diçen». Era ese episodio, y esa «nota» del alcalde, lo que le había movido a mandar al secretario real el Advertimiento: «y en quanto a esto del ser confessos los juezes, supplico a vuestra merçed vea esse papel que embío y lo enseñe a Su Magestad, que me pareçe no cumpliría con su serviçio, a que tam obligado estoy, si no lo advirtiesse» ${ }^{35}$.

El Advertimiento, por tanto, fue redactado como consecuencia directa de ese conflicto con el alcalde mayor de Plasencia y enviado a Vázquez el 15 de febrero de 1584. Siendo así, inmediatamente surgen algunas preguntas. La primera, evidentemente, es ¿por qué no lo mandó antes? Si Noronha tenía en su poder la información transmitida por Salvatierra desde alrededor de 1567, y mantenía correspondencia con Vázquez desde, al menos, mediados de 1580, ¿por qué espero cuatro años para transmitir tan importante información al rey? ¿Por qué no envió el Advertimiento mientras estaba en Portalegre, cuando, al parecer, su vida y la autoridad real peligraban por la acción de «los confessos»? Resulta verdaderamente extraño que recordara su reunión con Salvatierra tras ese episodio casi anecdótico con el alcalde mayor de Plasencia y no cuando los partidarios de don Antonio, que él consideraba «confesos», maquinaban contra él y contra Felipe II. Sorprende que una reunión ocurrida hacia 1567 hubiera sido, al parecer, olvidada en 1580, pero recordada con total nitidez cuatro años después, hasta el punto de recordar el contenido exacto de las cartas supuestamente entregadas por los cautivos. ¿Había el obispo recuperado de repente la memoria?

Y, sin embargo, Noronha no parecía estar del todo seguro, porque en su Advertimiento, tras hacer todo el relato de lo ocurrido durante su reunión con Salvatierra, añadía: «[su]ppuesto ser verdad lo que dicho tengo [...]». ¿Por qué ese supuesto? ¿Acaso el obispo dudaba de la veracidad de

\footnotetext{
${ }^{35}$ IVDJ, envío 91, caja 130, doc. 116.
} 
un episodio que aparentemente había vivido en primera persona? Parece que, efectivamente, dudaba; pero, en cualquier caso, Noronha añadía que, aunque no fuera del todo verdad lo que había contado, la experiencia mostraba «quam perjudiciales son a la república estos christianos nuevos». Este esquema de exposición recuerda sobremanera al que utilizó Diego de Simancas en su Defensa del estatuto de Toledo. Como vimos más arriba, también el inquisidor dudaba de la verosimilitud del rumor que corría sobre los judíos, pero inmediatamente pasaba a confirmarlo al contrastarlo con la experiencia: «con todo el subcesso de las cosas declaro quán cercano está a la verdad» ${ }^{36}$. Esta coincidencia resulta interesante y volveremos sobre ella después.

En cualquier caso, si el mismo Noronha dudaba de la veracidad de su relato, con más razón deberíamos nosotros dudar. Más aún teniendo en cuenta que en él se pueden identificar fácilmente varios errores y falsedades. Dejando de lado todo lo relativo a los cautivos - de lo que nos ocuparemos más adelante-, podemos constatar que es erróneo lo que afirma acerca de las becas en medicina y farmacia para «cristianos viejos»: Noronha habla de veinte en medicina y quince en farmacia, cuando, en realidad fueron treinta en medicina y cirugía ${ }^{37}$. En cuanto a lo que dice de los jueces, no hay constancia ninguna de que existiera esa «costumbre» de que en Portugal tuvieran que ser «cristianos viejos» ${ }^{38}$. Y, finalmente,

${ }^{36}$ BNE ms. 2592, p. 20; D. DE Simancas, Defensio statuti toletani, p. 19. Muchos años después, Francisco de Quevedo utilizó el mismo esquema: tras exponer parcialmente el contenido de la apócrifa correspondencia de los judíos de España y los de Constantinopla, dudó de su veracidad, pero no de que los judíos se habían comportado como en ella se decía: «Yo, Señor, no estoy tan cierto de que les diesen este consejo los judíos de Constantinopla a los de España, como de que los judíos de España le han ejecutado»; F. de Quevedo, Execración contra los judios, ed. de F. Cabo Aseguinolaza y S. Fernández Mosquera (Barcelona 1996) pág. 11.

${ }^{37}$ T. Braga, Historia, vol. 1, págs. 779-780.

${ }^{38} \mathrm{La}$ única disposición de este tipo que hemos encontrado se refiere exclusivamente al caso de Goa, y afecta únicamente a los recientemente convertidos. Se trata de una carta del rey Manuel I de 18 de febrero de 1519; véase A. J. SARAIVA, The Marrano Factory: the Portuguese Inquisition and its New Christians, 1536-1765 (Leiden - Boston 2001) pág. 347. En todo caso, las primeras disposiciones portuguesas contra el acceso de «cristianos nuevos» a la judicatura son de principios del siglo XVII; véase J. M. V. M. DE FIGUEIRÔA RÊGO, "A honra alheia por um fio»: os estatutos de limpeza de sangue no espaço de expressão Ibérica (sécs. XVI-XVIII), Tesis doctoral, Universidade do Minho (Braga 2009) págs. 56-57. 
lo que dice acerca del Concilio, suponiendo que se refiera al de Trento, es notoriamente falso que éste hubiera ordenado que los clérigos tuvieran que ser también «cristianos viejos» ${ }^{39}$.

Teniendo en cuenta que Noronha erraba o mentía cuando introducía datos meramente fácticos y que podían ser fácilmente verificados en la época, ¿por qué habríamos de creer una historia de cautivos y amoríos interreligiosos que tan fantástica parece, hasta el punto de asemejarse a una prefiguración del Guzmán el Bravo de Lope de Vega? ${ }^{40}$

A decir verdad, nuestra primera reacción ante el Advertimiento de Noronha fue de total incredulidad. Consideramos que todo su contenido era pura invención del obispo: que nunca tuvo lugar la confesión de los cautivos, que nunca se dio la reunión entre el obispo y el inquisidor Salvatierra, que éste no le entregó las cartas, que éstas nunca llegaron a manos del rey Sebastián I ni, desde luego, tuvieron papel alguno en la creación de esas becas en medicina y farmacia en la Universidad de Coimbra. Y, en todo caso, si el documento podía dar alguna pista acerca del origen y circulación de la famosa correspondencia apócrifa entre los judíos de España y los de Constantinopla, lo que mostraba en realidad era que, a principios de 1584, ésta podía manejarse como una novedad, pues Noronha pretendía dar a conocer algo que suponía desconocido en la Corte. Por tanto, el Advertimiento sería una evidencia de la tardía -y no de la temprana- circulación de la famosa correspondencia.

Sin embargo, al consultar la correspondencia entre Noronha y Vázquez en nuestro empeño por contextualizar mejor el documento, nos empezamos a hacer la siguiente pregunta: si todo era falso, ¿por qué el obispo de Plasencia mencionó a Salvatierra como fuente? Noronha no tenía necesidad de hacerlo, y sin embargo lo hizo; y al hacerlo corría el riesgo de que la veracidad de su historia pudiera ser comprobada: Vázquez podía consultar

${ }^{39}$ El Concilio decretó (sesión 23, cap. V) que sólo se debía examinar «el nacimiento de los mismos ordenandos, su edad, costumbres y vida»; véase El sacrosanto y ecuménico Concilio de Trento, traducido por Ignacio López de Ayala (2ª ed. Madrid 1785) pág. 367.

${ }^{40}$ Como se recordará, también Guzmán el Bravo cuenta la historia de dos cautivos cristianos que caen en manos de un judío que, en este caso, residía en Túnez. También en la novela de Lope la hija del judío se enamora de uno de ellos; véase L. DE VEGA, Guzmán el Bravo (Alicante 2004); M. ${ }^{a}$ R. LIDA, «Lope de Vega y los judíos», Bulletin Hispanique 75:1-2 (1973) págs. 73-112. 
con el obispo de Segorbe y descubrir así la mentira. De hecho, se sabe que Salvatierra, mientras ocupó ese obispado, estuvo en contacto con la Corte ${ }^{41}$. Era absurdo, pues, que el obispo de Plasencia corriera ese riesgo. Si mencionaba a Salvatierra, era muy posible que la historia proviniera realmente de él. Pero si era así, si efectivamente el antiguo inquisidor le había transmitido a Noronha todo lo que éste relataba en su Advertimiento, no tenía mucho sentido que hubiera informado de tan extraordinario descubrimiento a un obispo portugués y no al Consejo de la Suprema.

\section{De Felipe Botello a Andrés de Noronha}

En realidad, Salvatierra sí informó al Consejo de la Suprema Inquisición, y lo hizo de manera muy prolija. En el Archivo Histórico Nacional se conserva gran parte de la correspondencia que el inquisidor envió al Consejo durante su visita al maestrazgo de Alcántara entre finales del verano y principios del invierno de 1569. En ella informó de todos los pasos que daba, primero en Las Brozas, después en Alcántara y Valencia de Alcántara, y, finalmente, en Alburquerque ${ }^{42}$. Pero, de todas esas cartas, nos interesa destacar sólo una: aquella en la que menciona su entrevista con Andrés de Noronha.

Efectivamente, mientras se encontraba en Alburquerque, Salvatierra informó de que, durante su estancia en Valencia de Alcántara, había interrogado a una mujer portuguesa de ascendencia judía, la cual había pasado a Castilla llevando gran cantidad de dinero. Esta mujer le había informado de que había ocultado un pequeño tesoro cerca de Portalegre, y que, una vez establecida en Valencia, había mandado a un arriero a que lo recogiera. Por su parte, este arriero, al ser interrogado por el inquisidor, contó que en su camino en busca del tesoro se había encontrado con un hijo de la interroga-

\footnotetext{
${ }^{41}$ Ejemplo de ello es el famoso memorial contra los moriscos que envió a Felipe II en julio de 1587; véase P. Boronat y BarRachina, Los moriscos españoles y su expulsión: estudio histórico-crítico. 2 vols. (Valencia 1901) vol. 1, págs. 612-633. Aparte de eso, sobre Salvatierra no es mucho lo que se sabe; véase J. I. Martín Benito, «D. Martín de Salvatierra, obispo de Ciudad Rodrigo (1591-1604)», Centro de Estudios Mirobrigenses (2013), http://centrodeestudiosmirobrigenses.es/?p=419 [fecha de consulta: 11 de julio de 2016].

${ }^{42}$ Véase Archivo Histórico Nacional (en adelante AHN), Inquisición, leg. 2701, docs. 169, 181, 189, 190, 191, 192, 194, 197, 198 у 204.
} 
da, el cual le había contado que, cuando su madre se fue a Castilla, el obispo de Portalegre había apresado a una de sus hermanas y les había quitado toda su hacienda. Al conocer esto, Salvatierra preguntó por carta a Noronha, quien le respondió el día 21 de octubre diciéndole que todo era cierto, pero que no había ni rastro del tesoro, y que él creía que la mujer se había llevado todo su dinero a Castilla. No contento con esa respuesta, el inquisidor quiso verse con el obispo «por estar muy çerca de Valençia y entender de raíz la verdad». Marchó a Portalegre y debió de reunirse con Noronha entre finales de octubre y principios de noviembre, pues, aunque no sabemos la fecha exacta del encuentro, sí sabemos que, para finales de ese mes, el inquisidor se encontraba ya en Alburquerque, enfermo y en cama ${ }^{43}$. En cualquier caso, durante su charla, Noronha y Salvatierra concluyeron que los vecinos del lugar debían haberse hecho con el tesoro al saber de la huida de la mujer. El obispo, por su parte, informó al inquisidor de otro caso: un tal García López que había pasado a Castilla con «dos talegones de dinero» ${ }^{44}$.

A juzgar por el contenido de esa carta, parece que Salvatierra no consideró importante mencionar al Consejo nada acerca de esa parte de su entrevista con el obispo que, supuestamente, habría versado sobre la historia de los cautivos y las cartas de los judíos. ¿Por qué? ¿No lo consideró importante o quizás nunca hablaron de ese tema? ¿Era toda la historia de los cautivos pura invención de Noronha?

Lo cierto es que, a pesar de que no creyó conveniente mencionarlo en las cartas que envió al Consejo de la Suprema durante su visita ${ }^{45}$, a oídos de Salvatierra sí había llegado una historia sobre comunicaciones internacionales entre judíos. Esa historia, sin embargo, no tenía su origen en el testimonio de dos cautivos, sino en el de uno sólo, el cual no había estado en Constantinopla, sino en Ceilán -o, al menos, eso declaró él-. Lo sabemos porque el 28 de enero de 1570, estando ya de vuelta en Llerena, Salvatierra envió al Consejo un informe final sobre su visita, en el que se detallaba la «relaçión de las causas sentençiadas y determinadas» por él. Y, justo al final de esa relación, Salvatierra incluía copia de un fragmento

${ }^{43}$ Véase AHN, Inquisición, leg. 2701, doc. 194.

${ }^{44}$ AHN, Inquisición, leg. 2701, doc. 204.

${ }^{45}$ Quizás existan otras cartas de enero de 1570 que correspondan a la etapa final de su visita al maestrazgo de Alcántara, pues en AHN, Inquisición, leg. 2702 hay algunas de ese periodo que no pueden ser consultadas debido a su avanzado estado de descomposición. 
del memorial que Felipe Botello, «clérigo vezino de Valençia de Alcántara», le entregó para descargo de su conciencia ${ }^{46}$.

En ese «capítulo» se narra una historia que, al igual que la del $A d-$ vertimiento, parece increíble. Botello intenta alertar a la Inquisición de que judíos provenientes de Ferrara, Salónica, Ancona, Bolonia, Florencia, Roma o Aviñón, llegan a España como mercaderes haciéndose pasar por españoles. Y, para apoyar su afirmación, cuenta que, cuando estuvo cautivo en Ceilán, fue vendido a un judío de origen portugués, el cual le dijo muchas veces que no le importaba nada que en la Península se matara a tantos judíos ${ }^{47}$, puesto que, por cada judío que mataban los cristianos, «sus parientes» mataban a cien cristianos, ya que «unos heran médicos y otros boticarios, y otros letrados». Además, el judío mostraba estar en contacto con los judíos de Portugal y de España, puesto que cada año y medio le daba noticias de lo que allí sucedía. De hecho, por medio de la hija de su amo, Botello supo que éste mantenía correspondencia con la Península y con Italia. Por su información parecía como si los judíos hubieran creado un circuito permanente de correspondencia que unía a las comunidades judías de Europa con las de la India. En ese circuito no sólo se movían cartas, sino también dinero y personas. Así, Botello decía haber visto en Ferrara a unos judíos de Évora, a los que denunció y fueron llevados a la hoguera; y la hija del judío le informó de que desde España y otros lugares les enviaban dinero «para las juderías», aunque no le dijo con qué objeto. Tampoco logró saber quiénes eran los remitentes. En cuanto a la identidad de su amo, Botello señalaba que se llamaba «Rabi Chimi», pero que su nombre cristiano era Francisco, tenía alrededor de 70 años, era originario de Covilhã en Portugal, tenía el pelo canoso, era de mediana estatura y su hija se llamaba Ana. En cuanto a Ceilán, señalaba que era un reino «sugeto al Sophí».

\footnotetext{
${ }^{46}$ Véase el texto transcrito en el anexo. De Botello no sabemos casi nada. Entre 1582 y 1583 un cura llamado «Phelipe Botello», natural de Portalegre y vecino de Trujillo, de 63 años, fue acusado ante la Inquisición de Llerena del «delito de solicitación». Se le abrió proceso, se le reprendió y su caso fue cerrado. En cualquier caso, no podemos asegurar que se trate de la misma persona, a pesar de las coincidencias. Véase AHN, Inquisición, leg. 1987, exp. 11; AHN, Inquisición, leg. 1988, exp. 17; y AHN, Inquisición, leg. 1988, exp. 77.

${ }^{47}$ Botello habla de «los que acá mataban», no sabemos si se refería a Portugal o a Castilla, dado que habla de un judío de origen portugués, pero el testimonio se da en Castilla.
} 
Ése es el relato que el clérigo de Valencia de Alcántara transmitió por escrito a Salvatierra en 1569; un relato tan lleno de viajes, aventuras y sorprendentes confesiones, que parece del todo inventado. Sin embargo, a falta de otras fuentes con las que contrastarlo, resulta ocioso preguntarse sobre su verosimilitud. Lo más probable es que se trate de una mezcla de realidad y ficción. Todo lo que cuenta sobre los mercaderes judíos de otros países que, haciéndose pasar por cristianos, entraban en Castilla, tiene cierta base en la realidad ${ }^{48}$. Tampoco está alejado de la realidad lo que cuenta sobre la presencia de judíos de origen portugués en el subcontinente indio, acerca de sus movimientos internacionales y del envío de dinero y correspondencia entre las diferentes comunidades de descendientes de conversos y judíos ${ }^{49}$. El ejemplo más destacado de esto es, seguramente, el del médico García de Orta y su familia. De hecho, el padre de éste era originario, precisamente, de Valencia de Alcántara, pero, tras la expulsión de 1492, marchó a refugiarse a Castelo de Vide, cerca de Portalegre. Allí terminó convirtiéndose al cristianismo y contrajo matrimonio, y también allí nació García de Orta. Éste, tras estudiar medicina en Castilla, marchó en 1534 a la India, estableciéndose definitivamente en Goa. Allí ejerció como médico de varios gobernantes locales, así como de los virreyes portugueses. No mucho después, parte de su familia, que había sufrido persecución en Portugal, marchó a Goa para unirse a él. Sin embargo, tampoco allí encon-

${ }^{48}$ Tenemos noticia de este tipo de movimientos, pero, en general, se refieren a un periodo posterior. Véase N. MuchNiK, «Des intrus en pays d'Inquisition: présence et activités des juifs dans l'Espagne du XvIIe siècle», Revue des Études Juives 164:1-2 (2005) págs. 119-156; P. Huerga CRIADO, «El marranismo ibérico y las comunidades sefardíes», en Entre el islam y occidente: los judíos magrebíes en la Edad Moderna, ed. M. GARCíAArenal (Madrid 2003) págs. 49-68, y A. Domínguez Ortiz, «Judíos en la España de los Austrias», Nueva Revista de Filología Hispánica 30:2 (1981) págs. 609-616.

${ }^{49}$ Sobre los judíos y conversos en la India portuguesa véase J. A. Rodrigues DA SiLVA TAvim, Judeus e Cristãos-novos de Cochim: história e memória (1500-1662) (Braga 2003); y sobre los contactos que existían entre aquellos y los del Imperio otomano, véase, del mismo autor, «Portuguese New Christians in the Turkish "Carrefour" Between the Mediterranean and the Indian Ocean in the Sixteenth Century: Decentralization and Conversion», Journal of Early Modern History 17:5-6 (2013) págs. 561-584. Sobre el envío de dinero, con fines caritativos, entre las comunidades de conversos de la Península y las comunidades judías de la diáspora, véase, del mismo autor, «O auxílio que vem do "exterior": a tsedaqa dos cristãos-novos portugueses em Marrocos e no Império Otomano durante o século 16 - alguns exemplos», Journal of Sefardic Studies 2 (2014) págs. 168-191. 
traron descanso, ya que la Inquisición se estableció en esos dominios portugueses en $1560^{50}$. Varios familiares de García de Orta sufrieron entonces la persecución inquisitorial de manera cruenta. El mismo año que Botello entregó su memorial a Salvatierra, la hermana de García, Catarina, fue llevada a la hoguera. Después, la familia nunca pudo descansar. Ni siquiera los restos del difunto García pudieron hacerlo: en 1580, cerca de doce años después de su muerte, fue procesado, condenado, y sus huesos quemados en la hoguera. Años más tarde, en 1596, uno de los nietos de Catarina, Diogo de Orta, fue arrestado en Lisboa y acusado de crear una red internacional de comunidades judeoconversas que unía, entre otros lugares, Portugal, el Norte de África, el Imperio Otomano, Italia y la India, en la cual se movía tanto dinero como correspondencia ${ }^{51}$.

También hay algo de cierto en lo que menciona acerca de la presencia de judeoconversos portugueses en Ferrara. Allí vivieron, por ejemplo, Abraham Usque, y -antes de marchar a Constantinopla- Gracia Nasci. Sin embargo, no parece muy probable que el duque de Ferrara hiciera caso de la denuncia de Botello y llevara a la hoguera a esos «judíos» de Évora, pues, aunque no sabemos cuándo pudo estar el clérigo en Ferrara -ni si realmente estuvo allí-, lo cierto es que esa ciudad se había convertido desde principios del siglo XVI en un refugio para los judíos y conversos que huían de la Península. En 1550 el duque Ercole II llegó incluso a publicar un salvoconducto para que pudieran establecerse libremente en la ciudad. Si hubo persecución contra los judeoconversos en Ferrara, fue años después de que Botello entregara su memorial ${ }^{52}$.

${ }^{50}$ A. I. CANAS Da CUnHa, A Inquisição no Estado da Índia: origens (1539-1560) (Lisboa 1995).

${ }^{51}$ Véase J. Arrizabalaga, «Garcia de Orta in the Context of the Sephardic Diaspora», en Medicine, Trade and Empire: Garcia de Orta's Colloquies on the Simples and Drugs of India (1563) in Context, ed. P. FonTES DA Costa (Farnham 2015) págs. 11-32. Sobre el caso específico de Diogo de Orta véase A. Novinsky, «A familia marrana de Garcia de Orta, o “correio" dos judeus», en Mémorial I.-S. Révah: études sur le marranisme, l'hétérodoxie juive et Spinoza, eds. H. Méchoulan y G. Nahon (Paris 2001) págs. 357-369.

${ }^{52}$ Sobre la situación en Ferrara véase C. Rотн, A History of the Marranos (Skokie 2001 [1932]) págs. 208-209; CARo BAROJA, Los judíos, I, págs. 258-259. Sobre el caso de Gracia Nasci, véase C. Rотн, Doña Gracia of the House of Nasi (Skokie 2001 [1948]) págs. 65-81; M. D. Birnbaum, The Long Journey of Gracia Mendes (Budapest - New York 2003) págs. 54-65, y H. P. SAlomon y A. Di Leone, «Mendes, Benveniste, de Luna, Micas, Nasci: the State of the Art (1532-1558)», The Jewish Quarterly Review 88:3-4 (1998) págs. 135-211. 
Por otro lado, no tiene ningún sentido lo que dice acerca de que el reino de Ceilán estaba sometido al «Sophí». Como se sabe, en la Castilla del siglo XVI se conocía con el título de «sophí», o «sofí», al monarca safaví de Persia. Así se encuentra en, por ejemplo, el Viaje de Turquía o la Silva de varia lección ${ }^{53}$. Además, en la Sri Lanka del siglo XVI no existía ningún monarca que pudiera llevar ese título. De hecho, todos los reinos que convivían en la isla eran budistas ${ }^{54}$.

En cuanto a la confesión del supuesto amo judío de Botello acerca de los impulsos asesinos de los médicos, boticarios y letrados de origen judío, a no ser que demos por buenas todas las leyendas antijudías que corrían por la época, debemos considerarla totalmente apócrifa.

En cualquier caso, volviendo al asunto que nos ocupa -el origen y el contenido del Advertimiento de Noronha-, gracias al descubrimiento del memorial de Botello, ahora sabemos que Salvatierra recibió verdaderamente un testimonio de un testigo que estuvo, no en Constantinopla, sino en Ceilán; pero cautivo al fin y al cabo en casa de un judío de origen portugués, el cual le decía que los conversos de la Península que eran médicos, boticarios y letrados mataban a cristianos a placer, y cuya hija le habló de la existencia de correspondencia entre los judíos de Portugal -además de otros lugares de Europa-, y los de la India. En definitiva, los elementos más importantes del Advertimiento de Noronha están presentes en el memorial de Botello, solo que dispuestos de otra forma, quitando a uno de los cautivos, cambiando Ceilán por Constantinopla, y aderezándolo todo con elementos provenientes de otras fuentes. Por lo tanto, a no ser que pensemos que Salvatierra pudo haber recibido otros testimonios que contuvieran los mismos elementos, tenemos que concluir que el origen del Advertimiento está en este memorial de Botello.

Lo más probable, por tanto, es que las cosas sucedieran de la siguiente manera: Botello entregó su memorial a Salvatierra durante la visita que éste

Véase también P. Grunebaum-Ballin, Joseph Naci duc de Naxos (Paris 1968).

${ }^{53}$ C. DE Villalón, Viaje de Turquía (Valencia 2005) cap. «Las armas»; P. Mexía, Silva de varia lectión (Sevilla 1570) fols. 17v-18r. Véase también E. SÁNchez García, «Notas sobre la imagen de Persia en la prosa española del siglo XVI», en Memoria de la palabra: actas del VI Congreso de la Asociación Internacional Siglo de Oro. 2 vols., eds. M. ${ }^{a}$ L. Lobato y F. Domínguez Matito (Madrid 2004) vol. 2, págs. 1587-1597.

${ }^{54}$ Véase P. Peebles, The History of Sri Lanka (Westport 2006) esp. págs. 33-40. 
realizó al maestrazgo de Alcántara. El Inquisidor, que se encontraba en Valencia de Alcántara, marchó a Portalegre para reunirse con el obispo con el objetivo de tratar otro asunto; pero, casi con total seguridad, debió hablarle también del contenido del memorial entregado por Botello. Es posible que, incluso, le entregara una copia. Sin embargo, aún aceptando que el origen del Advertimiento está en el memorial de Botello, es obvio que entre ambos textos hay muchas diferencias. Así que, ¿cómo explicarlas?

Con respecto a esto, podemos adoptar dos perspectivas: pensar que Noronha mintió deliberadamente y fabricó una historia nueva a partir de elementos de varias fuentes, principalmente el memorial de Botello; o que mezcló esos elementos involuntariamente, debido a un problema de memoria. Nosotros nos decantamos por la segunda opción, por las siguientes razones:

En primer lugar, como hemos dicho, mentir conscientemente y, a la vez, citar a Salvatierra como fuente, no tenía mucho sentido. En segundo lugar, Noronha no tenía necesidad de mentir, pues, si en su Advertimiento hubiera hablado del contenido exacto del memorial de Botello, habría causado el mismo efecto que deseaba, que era alertar contra los jueces de origen converso y justificar la necesidad de la discriminación contra las personas de ese origen. En tercer lugar, desde su reunión con Salvatierra habían pasado más de 15 años, y es natural pensar que no podía recordar todos los detalles de lo que el inquisidor le había contado. La memoria de Noronha debía haberse resentido por el paso del tiempo. Ya tenía más de 60 años y la muerte estaba cercana -moriría dos años después-, la enfermedad hacía mella en él ${ }^{55}$, y recordemos que Noronha parecía haber olvidado lo que Salvatierra le había transmitido incluso cuando, en Portalegre, los que él creía «confessos», habían amenazado su vida. Además, hemos visto que el obispo de Plasencia erraba al hablar de las becas que se crearon en la Universidad de Coimbra. Es obvio que ya no recordaba bien algunas cosas. Por otro lado, aunque Salvatierra le hubiera entregado una copia del memorial, es muy posible que ya no la conservara, teniendo en cuenta que decía haberla enviado al rey Sebastián I. Además, desde entonces había cambiado de diócesis y, en el momento de escribir el $A d$ vertimiento, se encontraba en Béjar y no en su sede de Plasencia, donde

${ }^{55}$ Desde 1580 sufría de gota y en febrero de 1584, cuando escribió su Advertimiento, estaba tan enfermo que tenían que llevarlo en litera; véase IVDJ, envío 5, tomo II, doc. 186; IVDJ, envío 91, caja 130, doc. 117. 
guardaría todos sus papeles. En cualquier caso, aunque durante 15 años había olvidado su entrevista con Salvatierra, de repente la había recordado, al menos en parte. Pero ¿qué le había hecho recordar?

Con respecto a esto, sólo podemos especular. Sin embargo, es muy posible que su entrevista con Salvatierra le volviera a la memoria al caer en sus manos la Defensa del estatuto de Toledo de Diego de Simancas ${ }^{56}$. Recordemos que, por entonces, Noronha se enfrentaba a la oposición de su cabildo por sus intentos de evitar la ordenación de clérigos descendientes de conversos. Es muy posible que, con la intención de justificar su postura, leyera el único libro impreso que por entonces circulaba en defensa de los estatutos de limpieza de sangre. Además, esa salvedad que, al igual que Simancas, Noronha introdujo tras relatar su entrevista con Salvatierra, por la cual daba a entender que le cabían dudas acerca de la verosimilitud de su relato, pero que, al fin y al cabo, éste reflejaba bien lo que los judíos realmente habían hecho tras la expulsión, apuntaría en el sentido de que, efectivamente, el obispo de Plasencia se inspiraba en el libro de Simancas. Si es así, en él encontraría Noronha ese relato sobre el rumor que corría acerca de la correspondencia que los judíos de España supuestamente mantuvieron con los de las «sinogas de otros reynos». Habría recordado entonces lo que Salvatierra le había contado acerca del cautivo, de la correspondencia de los judíos de la Península con los de otros países, de la amenaza de los médicos, boticarios y letrados conversos. Habría recordado, pero en su cabeza los relatos de Simancas y Botello se habrían confundido, se habrían mezclado para dar forma al Advertimiento.

\footnotetext{
${ }^{56}$ Para cuando Noronha escribió el Advertimiento ya se había publicado La silva curiosa de Julián de Medrano, donde, como hemos visto, se podía leer la correspondencia entre los judíos de España y los de Constantinopla. Pero no parece muy probable que ese libro publicado en París unos meses antes hubiera llegado ya a manos del obispo de Plasencia. De hecho, no parece que esa edición de 1583 tuviera una amplia distribución en España, más bien al contrario. Así, en el Catálogo Colectivo del Patrimonio Bibliográfico Español sólo aparece un ejemplar: el conservado en la Biblioteca Nacional. Justo lo contrario de lo que sucede con la Defensa del estatuto de Diego de Simancas, de cuya edición de 1575 cabe encontrar hasta deciocho ejemplares. Así que resulta mucho más probable, como decimos, que la fuente de Noronha fuera Simancas.
} 


\section{CONClusión}

En el presente artículo hemos mostrado que Andrés de Noronha, obispo de Plasencia, envió su Advertimiento de çierto negoçio sabido por orden de la Inquisiçión de Llerena al secretario real Mateo Vázquez el 15 de febrero de 1584. Hemos mostrado también que el relato que Noronha insertaba en su documento, acerca de los cautivos que estuvieron en Constantinopla, fue un producto de su imaginación. Los cautivos nunca existieron, y, por lo tanto, nunca fueron interrogados por el inquisidor Martín de Salvatierra ni, evidentemente, le entregaron las famosas cartas. Éstas nunca estuvieron en manos de Noronha, ni éste pudo enviarlas al rey de Portugal. Por lo mismo, nunca pudieron desempeñar un papel en la creación de esas becas para «cristianos viejos» en la Universidad de Coimbra.

Sin embargo, aunque el relato era falso en casi su totalidad, tenía su origen en un documento real: un memorial entregado por el clérigo Felipe Botello a Martín de Salvatierra durante la visita que éste realizó al maestrazgo de Alcántara entre finales del verano y principios del invierno de 1569. En él, el clérigo alertaba sobre los movimientos internacionales de los judeoconversos, y añadía una historia acerca de su estancia como cautivo en Ceilán, en poder de un judío de origen portugués y de su hija, los cuales le mostraron que mantenían contacto epistolar con las comunidades judeoconversas de Europa.

La historia de Botello pudo llegar a oídos de Noronha de boca del propio Salvatierra, pues, como hemos demostrado, se reunieron efectivamente en Portalegre, entre octubre y noviembre de 1569. Es posible que Noronha enviara realmente al rey de Portugal información sobre lo que Salvatierra le había contado, es posible incluso que le enviara una copia del memorial de Botello, pero es evidente que éste no pudo influir en la creación de esas becas de la Universidad de Coimbra, pues, como sabemos, se crearon un año antes. Está por ver aún si el memorial pudo tener alguna influencia en el recrudecimiento de la presión inquisitorial sobre los descendientes de conversos que residían en las colonias portuguesas en la India.

En cualquier caso, parece que el memorial de Botello permaneció olvidado en la mente de Noronha durante mucho tiempo, a pesar de que en su vida ocurrieron diversos acontecimientos que hubieran debi- 
do llevarle a recordarlo. A pesar de ello, súbitamente, en 1584, el relato transmitido por Botello volvió a su memoria, quizás a causa de la lectura de esa historia acerca de la correspondencia que supuestamente los judíos de España mantuvieron con los de las sinagogas de otros países tras el decreto de expulsión de 1492, la cual se incluía en la Defensa del estatuto de Toledo del obispo Diego de Simancas. Quizás entonces los relatos de Simancas y Botello se mezclaron en la mente de Noronha hasta dar forma al Advertimiento.

Así, la forma en la que se transmitió el contenido del memorial de Botello es un ejemplo inmejorable de la manera en la que las leyendas -y las leyendas antijudías en particular-, se transmiten de boca en boca -en este caso, de manuscrito en manuscrito-, alterando su contenido, mezclándose con otras fuentes, añadiendo o quitando elementos del relato; en definitiva, haciendo bueno eso que señaló Jorge Luis Borges: «la realidad puede ser demasiado compleja para la transmisión oral; la leyenda la recrea de una manera que sólo accidentalmente es falsa y que le permite andar por el mundo, de boca en boca» ${ }^{57}$. Al parecer, la realidad también es demasiado compleja para la transmisión escrita.

La mezcla de realidad y ficción que ya contenía el relato de Botello se alteró de forma sustancial al mezclarse en la mente de Noronha con informaciones provenientes de otras fuentes -muy posiblemente el mencionado libro de Simancas-, dando como resultado un nuevo relato, una historia sobre la conspiración urdida entre los judíos de Portugal y los de Constantinopla. Así nació el Advertimiento que llegó a manos de Mateo Vázquez. Está por ver si tuvo alguna transcendencia. En concreto, queda por ver cómo se recibió en la Corte de Felipe II, si fue tenido en cuenta o arrumbado como una de las tantas acusaciones anticonversas que corrían por la época. En cualquier caso, en la Corte el contenido del texto de Noronha no debía resultar del todo extraño, puesto que el libro de Simancas -si hemos de creer lo que él mismo decía en su autobiografía- era allí conocido, hasta el punto de que el propio rey lo tenía en su alcoba ${ }^{58}$.

${ }^{57}$ J. L. Borges, Obras completas. 4 vols. (Barcelona 1992) vol. 2, pág. 334.

${ }^{58}$ D. DE Simancas, «La vida y cosas notables del señor obispo de Zamora don Diego de Simancas», en Autobiografías y memorias, ed. M. SERrano y SAnz (Madrid 1905) págs. 151-210. 
Finalmente, por todo lo dicho hasta aquí, podemos concluir diciendo que, si la famosa correspondencia apócrifa entre los judíos de España y los de Constantinopla no se manejó durante el proceso de aprobación y confirmación del estatuto de limpieza de sangre de la catedral de Toledo (1547-1556); si, como hemos probado, el inquisidor Salvatierra no entregó esa correspondencia, ni ninguna otra semejante, al obispo Noronha en 1569; y si, finalmente, como sostenemos, tampoco Diego de Simancas se refirió a ella en su obra de defensa del estatuto de Toledo (1575), sino sólo a una leyenda; entonces la primera referencia fechable que tenemos de su existencia son las propias cartas impresas en 1583 en la obra de Julián de Medrano. De hecho, si algo nos dice el Advertimiento con respecto a la historia de esa ficticia correspondencia, es que hacia principios de 1584 alguien tan importante como el obispo de Plasencia podía transmitir ideas como las contenidas en ella como si de una novedad se tratase, lo que vendría a demostrar que las famosas cartas no habían sido todavía difundidas en Castilla, al menos no en la medida en la que lo serían a partir del siglo XVII.

\section{Anexo: El Memorial de Felipe Botello (CA. 1569) $)^{59}$}

[f. 13r]Un capítulo de un memorial que Phelipe Botello, clérigo vezino de Valençia de Alcántara exhivió ante el señor ynquisidor liçençiado Salvatierra. Dize lo siguiente:

Quanto a lo demás, digo, señor, que yo no siento, como dicho tengo, mas que su merçed avía de tener grandýssima vigilançia en estos perros, en les preguntar si andan aquí o allá: judíos de Ferrara, Salonique, Ancona, Bolonia, Florençia, Roma, Aviñón. Porque destas partes suelen venir como mercadantes, y son lovos que hazen grandísima pérdida, porque sabrá cómo allá rezan la lengua portuguesa los de Portugal a los suyos, y los de Castilla lo mesmo, y, como yndustriados en la lengua, mudando el ávito en español, como saben las lenguas, entran a hurto. Porque estando cautivo en el rreyno de Çeilán me vendieron a un judío, el qual se llamava Rabi Chimi, hombre mayor, renegado, natural que debía ser de Cuvillana [i.e. Covilhã] del reino de Portugal, y acá se dezía llamar Françiscus. Fuese de aquí muchacho de diez y ocho hasta veinte años, y muchas vezes me dezía que no se dava nada de los que acá matavan,

${ }^{59}$ AHN, Inquisición, 1988, exp. 74, fols. 13r-14r. 
que si matavan çiento, matavan sus paritentes por cada uno çient christianos, que unos heran médicos y otros boticarios, y otros letrados. Este dicho perro nos dava nuevas cada año y medio de Portugal y de España, y de los que penitençiavan, como si los viera. Savido de una hija suya cómo lo savía, dixo que los judíos de Portugal, todos, ocurrían con sus cartas a Lisbona, al Algarve; los de Castilla a Sevilla o Sanlúcar de Barrameda y a otros puertos de mar, y por medio de mercadantes de Valladolid, Madrid, que escriven a Ytalia, $\left.{ }^{[f .}{ }^{13 v}\right]$ y los de Ytalia, por medio de Veneçia, Ancona, Ferrara.

Y más, señor, me acuerdo que, hallándome en Ferrara caminando, conoçí judíos de Évora çiudad, y savido como heran judíos, los fuimos a denuçiar [sic] al duque, el qual se holgó mucho, y después, estando en Roma con un tío mío portugués, clérigo de missa, capellán de el cardenal de Nápoles, tuvimos nuevas cómo los avían abrasado. Phelipe Botello.

Passó ante mi,

Pedro de los Ríos.

Yten dixo más en otro papel que después presentó lo siguiente:

Digo que el reyno de Çeilán donde yo estuve cautivo es sugeto al Sophí, según dezían, y el dicho Francisco, de quien tengo dicho, es hombre de setenta años poco más o menos, cano todo, de mediana estatura, y no sé cuyo hijo es, ni qué parientes tiene en Cuvillana. Tampoco sé, ni sospecho, qué personas son en particular las que enbían recaudos, cartas y dineros a las juderías de Ytalia y de Oriente, porque el dicho Francisco no me lo dixo, porque se me çerró en esto, ni yo lo pude entender de su hija, ni de nadie más de lo que dicho tengo, y ansí mesmo la dicha hija del dicho Francisco, que se llama Ana, me dixo cómo de España les enbiavan dineros para las juderías, y de otras partes, ${ }^{[f .14 r]}$ que no me lo declaró para qué efecto ni para qué, ni por qué vía los ymbiavan, y esta es la verdad, so cargo del juramento que tengo hecho, y fírmolo de mi nombre. Phelipe Botello.

Pedro de los Ríos.

Recibido: $26 / 07 / 2016$

Aceptado: 18/11/2016 